This is an electronic version of an article published in:

Labelle, P.R. (2007). Initiating the learning process: A model for federated searching and information literacy. Internet Reference Services Quarterly, 12(3/4), 237-252. doi:

10.1300/J136v12n03_01

Internet Reference Services Quarterly is available online at

http://www.informaworld.com/smpp/content $\sim \mathrm{db}=\mathrm{all}$ ? content $=10.1300 / \mathrm{J} 136 \mathrm{v} 12 \mathrm{n} 03 \_01$

\title{
Initiating the learning process: \\ a model for federated searching and information literacy
}

\author{
Patrick R. Labelle \\ Instruction/Reference Librarian \\ Concordia University Libraries \\ 1455 de Maisonneuve Blvd. W., LB-209 \\ Montreal, QC \\ H3G 1M8 \\ CANADA \\ Telephone: (514) 848-2424, ext. 7685 \\ Fax: (514) 848-2882 \\ E-mail: patrick.labelle@ concordia.ca
}

\begin{abstract}
Access to federated search tools is increasing and many academic libraries are now looking beyond implementation, and are considering the broader implications of federated searching such as its impact on information literacy programs. Although this emerging technology is still experiencing acknowledged growing pains, its potential for transforming the way students conduct research is promising. Reviewing information seeking behavior research and analyzing how federated searching fits within the Association of College and Research Libraries' Information Literacy Competency Standards for Higher Education (2000) enables academic librarians to consider an integrative instructional model that utilizes federated searching as a way of initiating the learning process.
\end{abstract}

Keywords - information literacy, federated searching, information seeking behavior, native interface searching, instruction, teaching, learning, instructional design

\section{Introductory footnote}

Patrick R. Labelle (patrick.labelle@ concordia.ca) is Reference/Instruction Librarian at Concordia University Libraries, 1455 de Maisonneuve Blvd. W., Montreal, Quebec, Canada, H3X 2S3. 


\section{Initiating the learning process: \\ a model for federated searching and information literacy}

\section{Introduction}

Federated searching is bringing about rapid change to the academic library landscape as it provides information seekers with the ability to search simultaneously across multiple databases, library catalogs and search engines from a single access point. Federated search tools can definitely be appealing to novice searchers such as undergraduate students who, faced with an ever-increasing number of resources, remain unfamiliar as to which tools will best meet their needs. For graduate students and researchers conducting literature reviews, these tools might help uncover relevant resources that could otherwise be overlooked.

Regardless of potential usefulness, the reliability and trustworthiness of federated search tools, at this early stage of development and implementation, are problematic if not worrisome. Known issues and limitations such as relevancy ranking, de-duplication, incomplete profiling of resources, lack of advanced search capabilities, and inability to utilize thesauri and controlled vocabulary, can and do influence librarians' willingness to integrate the teaching of federated search tools within information literacy instruction. Nevertheless, according to Luther (2003), Hane (2003), and Terrell (2004), access to federated search tools is increasing and many academic librarians are now looking beyond implementation, contemplating the broader implications of federated searching such as its impact on information literacy programs.

By reviewing research on information seeking behavior and by analyzing how federated searching fits within the Association of College and Research Libraries' 
Information Literacy Competency Standards for Higher Education (ACRL 2000), it is possible to propose an integrative model that allows academic librarians to better position themselves vis-à-vis this emerging technology and to adapt their learning outcomes, course content, instructional strategies and assessment methods in ways that highlight the place and value of these tools within the information research process.

\section{Limitations of federated searching}

Federated search tools are far from perfect, as a cursory glance of the literature on the topic attests. In fact, numerous authors have opined on the limitations, drawbacks and disadvantages that such tools present to a variety of users. The origins of these observations and criticisms can be traced back to the literature on Web metasearch engines. Although the sophistication of these tools has improved over time, initial reactions focused on their inability to translate a search query to the correct syntax required by the individual search engine, their lack of advanced search features, their ambiguous ranking mechanism, which listed only the highest ranked results, and their tendency to abandon comprehensiveness over speed (Repman and Carlson 1999). Most of these shortcomings are also discernable in today's federated search environment.

\section{Lack of functionality}

As searches may, more often than not, be imprecise and obscure, federated search functionality is not optimal (Arant and Payne 2001). The sophistication of federated search tools is limited, which results in an inability to take advantage of individual resources' advanced search features, limit options, thesauri and subject-specific indexing. Failing to access value-added attributes significantly diminishes the usefulness of federated searching and actually raises questions about its overall purpose (Luther 2003). 
Why would someone use a federated search tool if it will not provide him or her with the best possible results? Why should librarians be bothered with teaching students to use these tools if they are plagued by important limitations and do not provide comprehensive access to all online library resources? In reality, all search tools have limitations that hinder their effectiveness and users are responsible for recognizing these when assessing the value of each tool. This should be no different within a federated search environment. Result retrieval and display

Result retrieval and display comprise another shortcoming of federated searching as results seem to mysteriously appear in a single list without any clear indication as to how they are found, presented, classified and sorted. Although it is possible to sort results once obtained, users are left to wonder exactly how a search is interpreted to begin with. Sadeh (2004) mentions that the display of results is not as straightforward as users expect, given their knowledge of and experience with Web search engines that present results by relevance. Some federated search tools offer relevancy ranking, yet it is based solely on the citation information that is retrieved and, therefore, is of limited value (Cox 2006). Accurate and complete relevancy ranking does not seem attainable, as federated search tools cannot access resource-specific indexing that content providers generally use to rank results. In addition, these tools do not replicate identical searches in each selected resource, which eliminates the possibility of creating an authentic search that considers relevancy in the same way throughout resources (Hane 2003). Although relevancy ranking would be a positive enhancement for federated search tools, rarely is this option used, by default, in library catalogs and article databases, which actually sort results by 
recency rather than relevancy. Students will often prefer to obtain current results, making the argument over relevancy ranking a moot point.

\section{De-duplication}

De-duplication, on the other hand, still represents a significant challenge, even though limited de-duplication is already possible. For instance, following a search, duplicate results can be identified and grouped together under a single entry. However, these duplicates represent only those results that the federated search tool retrieved, and does not consider the entire set of potential results. For that reason, Hane (2003) argues that true de-duplication will likely never occur, as this would require considerable time to complete in order for all results obtained from each resource to be compared against each other.

The overall value and effectiveness of federated search tools within an academic context remains questionable when issues such as limited functionality, results display, relevancy ranking and de-duplication persist. Federated searching is an emerging technology that is accompanied by acknowledged growing pains, but its potential for transforming the way students conduct research is nonetheless promising.

\section{Potential of federated searching}

According to Fryer (2004), users expect an interface as streamlined as Google's, one that is uncomplicated and intuitive, and that does not require a steep learning curve. She also contends that partial de-duplication is better than nothing; that the reduced time it takes to do a basic search is benefit enough; and that federated searching represents a good starting point when conducting research. Crawford (2004) echoes this perspective by stating that the allure of the single search box will satisfy users who no longer need to 
worry about which of several hundred databases best suit their needs. A simple search interface may lead students to retrieve combined results relating to their topic while increasing the overall use of underutilized resources (McCaskie 2004). By doing so, students may locate useful information in resources that they may have not considered searching (Baer 2004). Federated searching can allow students to quickly enter and discover the wealth of scholarly information that is available.

When designing environments that foster information literacy learning, academic librarians must consider both the known limitations as well as the practical applications in order to meaningfully engage students in the research process. In addition, librarians must not discount past experiences and behaviors that students bring to the classroom setting.

\section{How students seek information}

Much of the resistance to federated searching stems from its shortcomings. Librarians shy away from promoting tools and services that are not fully functional or reliable (McCaskie 2004). They are reluctant to introduce tools that threaten completeness for fear that this will hamper overall search effectiveness. However, students rarely seek breadth and depth when searching. In most cases, they are novices who remain satisfied with "good enough" results that information professionals would probably find unsatisfactory (Luther 2003; McCaskie 2004; Miller 2004). When thinking about federated searching, librarians need to consider both students' expectations of search tools as well as their information seeking habits and behaviors. 
The need for speed

Anecdotal evidence and observation of students' use of library resources is indicative of the steps they take to seek information. Seldom do students spend an inordinate amount of time searching for material needed for their assignments (Kuhlthau 2004; Weiler 2005). They look for and are usually satisfied with results that match assignment-specific criteria. For the Google generation, the quality of results is not as important as the process, which must be simple, quick and efficient (Luther 2003; Weiler 2005). Familiarity with and reliance on Web search engines for information research purposes seem to indicate that students prefer ease-of-use and speed over relevance and depth (McCaskie 2004). Webster (2004a) observes that next generation searchers have little patience and tolerance for using multiple search interfaces to locate online information from disparate sources. Students, who do not know and who do not care to know the differences between catalogs, databases, online aggregators and other resources, are likely to opt for single search tools rather than having to replicate the same strategy in multiple search tools (Sadeh 2004; Tallent 2004; Webster 2004b). For students, the appeal of federated searching lies in its ability to provide a single point of entry to the literature that mirrors the functionality of the Web environment.

\section{Usability study results}

Tallent (2004) conducted an informal usability study at Boston College Libraries to discover how students utilize their federated search product, MetaLib. Results of focus group discussions confirm numerous assumptions concerning information seeking behaviors. Of note, students prefer the straightforwardness of keyword searching and usually ignore system-supplied enhancements as well as alternative search options. 
Favoring search interface simplicity to sophistication, students do not read instructions or seek online help to improve the way they use a database or catalog. Tallent observed that students instinctively prefer to search immediately in one resource rather than search thoroughly by replicating strategies in many. Also, students seem satisfied with the first reasonable results they obtain and rarely aim for comprehensiveness. When asked, students admitted they would broaden their choices if they could search simultaneously across resources. Tallent's research findings fuel the argument that students might not want or need comprehensive results when conducting research.

Types of searchers

The notion of comprehensiveness is also discussed in research conducted by Heinström (2005), who found that students' personality and study approach influence their information seeking behavior. Students were categorized as either fast surfers concerned with gathering information quickly and easily, broad scanners involved in locating information from a wide range of sources or deep divers engaged in in-depth research of high quality information. Heinström states that even though personality traits will likely remain consistent in any given situation, the context of the search environment itself may impact a student's level of engagement when seeking information. According to her descriptions of both fast surfers and broad scanners, it is possible to surmise that federated searching might be an attractive option for those students wanting quick information from an array of sources. In addition, deep divers could also benefit from federated searching's ability to query a multitude of resources in order to uncover potentially useful options deserving further investigation. 


\section{Kuhlthau's information search process}

According to Kuhlthau's (2004) fifth stage of the information search process, students should collect information by using library resources, request assistance from librarians and take detailed notes along with bibliographic citations. Subsequent research conducted by Kuhlthau (2004) demonstrates that, at this stage of the process, students develop personal systems for collecting information that do not always include methods presented by librarians in traditional instruction. What this valuable research on information seeking behavior indicates is that students, regardless of the instruction they receive, develop their own techniques and strategies for finding information.

In light of the research conducted on students' information seeking behavior, librarians should review and assess current practices to analyze how students actually perform within an information landscape dominated by multiple formats and resources. Perhaps then perceptions would change about federated searching's purpose in academia.

\section{Considering the ACRL Standards}

Since being adopted in 2000, the Association of College and Research Libraries' Information Literacy Competency Standards for Higher Education (ACRL 2000) guide many academic libraries in their information literacy-related activities, from instructional design to assessment and from workshop planning to curriculum-integrated instruction. These standards are not peripheral; they play a vital role in focusing librarians' efforts and in shaping information literacy success. It is therefore imperative that strategies for integrating the teaching and learning of federated search tools, within the academic context, be achieved through serious reflection on practices best corresponding to the standards. By analyzing each standard, similarly to Terrell's (2004) analysis of the 
Australian and New Zealand Information Literacy Framework and to Cox's (2006) interpretation of the ACRL Standards, it is possible to identify instances where federated searching can be beneficial to both the instructor and the learner.

\section{Determining the nature and extent of the information needed}

Standard One requires that, at this early stage of the research process, students be able to not only articulate their information need, but also identify a variety of types and formats of information sources. Source identification remains a formidable task, complicated only by the constant increase of available options. Most federated search tools provide results from a variety of sources without any clear identification. This situation requires that students develop skills enabling them to accurately read and understand citations (Cox 2006). In addition to grouping resources by broad subject categories, federated search tools can be used to combine resources by type of information such as reference material (online encyclopedias, dictionaries, etc.), books (library catalogs), articles (by type - newspapers, magazines, journals) and others (standards, conference proceedings, theses, etc.). By providing this second level of categorization, even though distinctions between resources are not always evident and clear-cut, librarians can present students with reliable choices that allow them to explore topics and conduct preliminary research across authoritative resources.

Federated search tools can also simplify the search process by allowing students to dedicate more time to interpreting and integrating the information they find rather than searching for it. As Tallent (2004) reported, students conduct quick searches and expect

useful results. They do not spend a great deal of time learning search interfaces and rarely consult instructional material. Performing a quick federated search may provide them 
with an overview of what is available, which can help them determine the nature and extent of the information they need (Cox 2006). Accessing needed information effectively and efficiently

Resistance towards federated searching's place within the information literacy spectrum emanates from the false notion that these tools eliminate the need for students to select the most appropriate investigate methods and information retrieval systems. Those students who are information literate are capable of choosing search tools that will best meet their needs, and can construct and implement effectively designed search strategies. A respondent to an e-mail survey conducted by McCaskie $(2004,59)$ states that "[...] librarians $[\ldots]$ are hesitant to tell students to use something that searches across resources because we are also trying to make the students information literate and to help them learn how to distinguish one type of resource from another." This is, however, a narrow-minded perspective that does not consider the wider value of viewing federated searching as a means of discovering resources. Well-designed federated search tools can facilitate and improve source selection without removing the need for students to investigate the scope and content of each individual resource.

Information literacy instruction aims to develop transferable skills that allow students to become independent and critical users of information. Federated searching does not hinder the achievement of this objective. In fact, it encourages students to consider different options by analyzing results obtained from multiple tools before selecting one that might be worth investigating independently. Students can then discover the richness of resource-specific search features such as thesauri and controlled 
vocabulary that can be used to perform more sophisticated searches, even though students generally ignore such options and features (Tallent 2004).

Standard Two of the ACRL Standards focuses heavily on individual resource characteristics and does not account for metasearch or federated search technology's growth in recent years. Learning outcomes that deal solely with using resource-specific features such as thesauri, search syntax, limit options, etc., must be adapted to consider the realities of federated searching. As with any other search tool, students should reflect on the advantages and disadvantages of federated searching in order to develop decisionmaking abilities that can be applied when choosing appropriate search tools based on various information needs (McCaskie 2004; Zimmerman 2004).

\section{Evaluating information and its sources critically}

Standard Three focuses mainly on the need for students to develop critical thinking skills as they evaluate the quality of the information they find before integrating it into their knowledge base and value system through summary, synthesis, comparison and interpretation. Given that the boundaries relating to the teaching of critical thinking skills are imprecise (are faculty members or librarians responsible?), librarians tend to focus primarily on source evaluation rather than on content evaluation (Terrell 2004). With federated search tools retrieving large sets of results, evaluation of these results is even more critical than before (Cox 2006). Librarians must ensure that students acquire abilities that allow them to judge the quality of the information located through various sources.

Consequently, an information literate student determines if the initial query should be revised, reviews information retrieval systems used and expands to include 
others as needed. In a traditional search environment, students would evaluate whether they gathered sufficient information to satisfy their need. If not, they would need to review their search strategy in order to expand sources consulted. In a federated search environment, evaluating retrieved information is simplified, to a certain extent, as various sources are queried at the same time making it easier for students to sort and de-duplicate results from a single set. However, the fuzziness of the federated search environment actually provides increased opportunities for students to perfect and apply critical thinking skills.

\section{Using information effectively to accomplish a specific purpose}

When surveying performance indicators and outcomes listed under Standard Four, an information literate student is expected to use information in the process of creating a product such as writing a research paper. Federated searching's overall impact on the attainment of this standard is barely noticeable (Cox 2006). One of the outcomes states that students should maintain a journal or log of activities relating to the information seeking, evaluation and communicating processes. It may be worthwhile to analyze research logs or journals to compare experiences of those students who use native interface searching to those who utilize federated searching. This might provide valuable insight as well as a better understanding of how students go through the information research process using different search technologies.

Standard Four also maintains that an information literate student integrates new and prior information in a manner that supports the product he or she is creating. Although the imprecision of federated search tools can impede on the quality of results retrieved upfront, these tools can, conversely, increase the quantity of information 
available. Assessing and comparing bibliographies prepared by students using federated search tools may be indicative of a greater range of information sources. Further research is required to confirm the impact of these tools on the ability for students to use information effectively.

Understanding various issues surrounding access to and use of information

Standard Five deals with how an information literate student understands the many legal, economic, ethical and social implications of accessing and using information. Because federated searching blurs the way in which information can be accessed, it might impair students' understanding of these numerous implications (Terrell 2004). Regardless of the way information is accessed, students still need to learn about copyright, plagiarism, proper use of citation/documentation styles as well as institutional policies governing access to information resources. Instruction surrounding these implications and issues does not change with the introduction of federated searching.

By systematically reviewing the ACRL Standards, especially Standards One and Two, it is evident that federated searching presents significant challenges for information literacy instruction that require librarians to modify current practices so students can achieve competence within this new search environment and to tailor instructional strategies that utilize this technology to initiate the learning process.

\section{Initiating the learning process}

The analysis of the ACRL Standards forms the basis for developing and presenting a practical model that builds on federated searching's strengths, without discounting its weaknesses. As is the case with other search tools, federated searching has its place in academia, one that may be debatable and even disputed, but one that may 
likely gain more prominence as improvements and enhancements are made. Therefore, by proposing an instructional model that integrates federated searching within the information literacy framework, it is possible to design learning environments that emphasize the uses and limitations of these tools within the information research process while meeting students' needs.

\section{Current models}

McCaskie (2004) conducted interviews with librarians at four universities in the United Kingdom to determine how federated searching was being introduced through instructional activities. At one university, federated searching is integrated into general sessions as a means of accessing databases. Students learn the same search techniques as before as well as how to evaluate and select results. However, less time is spent on explaining how to choose databases, which results in more time devoted to discussing how results are returned from each resource. At other universities, interviewees mentioned that federated searching simplifies the process of resource selection and access. Instructional activities focus on federated searching's ability to act as a resource discovery utility that students can use to either search multiple resources simultaneously or to independently query resources through native interfaces. In these sessions, both search options are presented and explained to students. Discussing the pros and cons of all possibilities allows librarians to use an inclusive approach to teaching information research, which focuses less on the tools themselves and more on transferable critical skills and knowledge that information literacy instruction aims to achieve. 


\section{Resource discovery}

Students are not fully utilizing library resources when conducting research. Federated searching should be used to lure novices adept at searching Google to consider the value of library resources by pointing them to the literature in their field of study (Luther 2003). In fact, resource discovery is one of the major advantageous applications of federated searching, which allows students to compare and contrast results obtained from various individual resources in order to discover those that might be better suited to satisfy an information need (Arant and Payne 2001; Feeney and Newby 2005; McCaskie 2004; Tallent 2004). Federated searching presents an unparalleled advantage over the trial and error method currently employed by many first-time users.

Resource selection is at the heart of the debate surrounding federated searching. Some librarians argue that federated searching removes the need to learn about selecting appropriate search tools, investigating their scope, content and organization, choosing controlled vocabulary, and assessing the quality, quantity and relevance of search results (Baer 2004; Frost 2004). This is true only if these tools are seen as the first and only step in the information research process. However, when viewed differently, federated search tools can actually help students improve information proficiency by acting as key entry points to unfamiliar resources. Instead of thinking about federated searching as "a step backward, a way of avoiding the learning process" (Frost 2004, 68), librarians should view it as a resource discovery utility that can assist students, mainly at the undergraduate level, in locating information and in identifying pertinent resources. Librarians can subsequently select among those valuable resources to further explore their uniqueness. This is a good opportunity to discuss native interface searching and, more importantly, to 
introduce such features as controlled vocabulary and thesauri. Federated searching is then seen as a step forward.

\section{Modifying behavior}

When searching for information, students will utilize strategies that have worked in the past (Leckie 1996). If they use the Web for academic research and have not been introduced to other search possibilities, they will likely turn to the Web again when faced with a new information need (Weiler 2005). This is a challenge librarians face when introducing library resources as search alternatives. The search interfaces in many such resources are not always intuitive and easy-to-use. Federated searching provides opportunities to teach students about academic research by introducing search tools that they will want to use (Cox 2006). The single search box model that most federated search tools employ provides a way for librarians to bridge the gap between Web searching and database or catalog searching. If librarians can wean students from the Web by presenting them with a similar tool that yields more scholarly results, then part of the process of developing their ability to choose appropriate information retrieval systems will be attained.

Students must also develop essential critical thinking skills relating to the evaluation of the information they find in a federated search environment. The focus of information literacy instruction should be on facilitating students' development of these skills through discussion and analysis. Teaching moments should not only cover basic features, but also include critical discussion on the use of different search tools (Zimmerman 2004). Learning activities can engage students in comparing results from a 
federated search to those obtained in a native interface search so that they may develop their own critical diagnosis of federated searching's usefulness in the research process.

\section{Conclusion}

Information literacy has evolved over time to encompass new ways of thinking about information research that differ from its bibliographic instruction origins. The transition between traditional tool-based teaching to a more holistic approach to information use in academia and in everyday life has required a significant shift in the way librarians design and deliver instructional programs. Due to ongoing technological developments and innovations, these programs are constantly being revised and updated to provide learners with meaningful and engaging opportunities to acquire skills and knowledge to help them thrive within an increasingly information-intensive environment.

Federated searching represents a major change in information access and retrieval. Librarians are at a crossroads and need to determine how best to utilize the potential that this technology brings to the instructional landscape. Should librarians ignore issue-plagued federated search tools entirely or should they admit that these tools, although imperfect, serve a purpose? The stance that librarians take is dependent on a variety of factors, including whether or not instruction is viewed as being instructor- or learner-centered.

From a pedagogical standpoint, it is important to consider students' prior knowledge and behaviors as these contribute to the learning environment in which librarians teach. Insightful research on students' information seeking behavior needs to be taken into account when librarians design instructional goals, strategies and activities. Students' preferences for quick and efficient searching over in-depth and thorough 
investigation warrant further attention in deciding if, when and how federated searching is introduced. In addition, those librarians who vehemently stand by the ACRL Standards must adopt a more lenient interpretation of indicators and outcomes that allows for technological innovations to take their place within the information research process.

Federated searching has arrived and librarians can no longer ignore the impact that it will have on information literacy instruction. Based on Terrell's (2004), Cox's (2006) and the present analysis, this impact will likely not pose a serious threat to the foundational principles of information literacy. This new technology has promise and potential applications that can benefit learners on many levels, none more important than how it can assist librarians in initiating the learning process. 


\section{References}

Arant, Wendi, and Leila Payne. 2001. The common user interface in academic libraries: Myth or reality? Library Hi Tech 19 (1): 63-76.

Association of College and Research Libraries. 2000. Information literacy competency standards for higher education. Chicago, IL: American Library Association. Also available online at http://www.ala.org/ala/acrl/acrlstandards/informationliteracycompetency.htm

Baer, William. 2004. Federated searching: Friend or foe? College \& Research Libraries News 65 (9): 518-519.

Cox, Christopher. 2006. An analysis of the impact of federated search products on library instruction using the ACRL Standards. portal: Libraries and the Academy 6 (3): 253267.

Crawford, Walt. 2004. Meta, federated, distributed: Search solutions. American Libraries 35 (7): 80.

Feeney, Mary, and Jill Newby. 2005. Model for presenting resources in Scholar's Portal. portal: Libraries and the Academy 5 (2): 195-211.

Frost, William J. 2004. Do we want or need metasearching? Library Journal, April 1, 68. Fryer, Donna. 2004. Federated search engines. Online 28 (2): 16-19.

Hane, Paula J. 2003. The truth about federated searching. Information Today 20 (2): 24.

Heinström, Jannica. 2005. Fast surfing, broad scanning and deep diving: The influence of personality and study approach on students' information-seeking behavior. Journal of Documentation 61 (2): 228-247. doi: 10.1108/00220410510585205. 
Kuhlthau, Carol Collier. 2004. Seeking meaning: A process approach to library and information services. 2nd ed. Westport CT: Libraries Unlimited.

Leckie, Gloria J. 1996. Desperately seeking citations: Uncovering faculty assumptions about the undergraduate research process. Journal of Academic Librarianship 22 (6): 201-208. doi: 10.1016/S0099-133(96)90059-2.

Luther, Judy. 2003. Trumping Google: Metasearching's promise. Library Journal, October 1, 36-39.

McCaskie, Lucy. 2004. What are the implications for information literacy training in higher education with the introduction of federated search tools? MA thesis, University of Sheffield. Also available online at http://dagda.shef.ac.uk/dissertations/2003-04/External/McCaskie_Lucy_MALib.pdf

Miller, Todd. 2004. Federated searching: Put it in its place. Library Journal, April 15, 32. Repman, Judi, and Randal D. Carlson. 1999. Surviving the storm: Using metasearch engines effectively. Computers in Libraries 19 (5): 50-55.

Sadeh, Tamar. 2004. The challenge of metasearching. New Library World 105 (3/4): 104112. doi: $10.1108 / 03074800410526721$.

Tallent, Ed. 2004. Metasearching in Boston College Libraries - a case study of user reactions. New Library World 105 (1/2): 69-75. doi: 10.1108/03074800410515282.

Terrell, John. 2004. Cross database searching: Information literacy for the 'real world'? Paper presented at the Lifelong Learning Conference, Yeppoon, Australia. Also available online at http://lifelonglearning.cqu.edu.au/2004/papers/terrell-133paper.pdf 
Webster, Peter. 2004a. Breaking down information silos: Integrating online information. Online 28 (6): 30-34. . 2004b. Metasearching in an academic environment. Online 28 (2): 20-23.

Weiler, Angela. 2005. Information-seeking behavior in generation Y students: Motivation, critical thinking, and learning theory. The Journal of Academic Librarianship 31 (1): 46-53. doi: 10.1016/j.acalib.2004.09.009.

Zimmerman, Devin. 2004. Metasearching's teaching moments. Library Journal, September 1, 54 . 